\title{
Tensile properties of segmented block copolymers with monodisperse hard segments
}

\author{
G. J. E. Biemond · J. Feijen · R. J. Gaymans
}

Received: 7 January 2008/Accepted: 12 March 2008/Published online: 4 April 2008

(C) The Author(s) 2008

\begin{abstract}
The tensile properties of segmented block copolymers with mono-disperse hard segments were studied with respect to the hard segment content (16-44 wt.\%) and the temperature $\left(20-110^{\circ} \mathrm{C}\right)$. The copolymers were comprised of poly(tetramethylene oxide) segments with the molecular weights of 650-2,900 Da and of mono-disperse bisester-tetra-amide segments (T6A6T) based on adipic acid (A), terephthalic acid (T) and hexamethylene diamine (6). An increasing content of T6A6T gave rise to an increased modulus, yield stress and fracture stress. The modulus could be modeled by a composite model. Moreover, a strain-softening was observed well below the yield stress, due to the shearing of the T6A6T crystallites. At strains $>200 \%$, a strain-hardening of the PTMO segments took place and this even for PTMO segments that were amorphous in the isotropic state. The strain hardening increased the tensile properties. An increase in temperature had little effect on the modulus of the copolymers, but was found to lower the yield and fracture stresses. At temperatures above the melting temperature of the oriented PTMO, no strain-hardening took place. The yield stress as a function of temperature could be described by the Eyring
\end{abstract}

G. J. E. Biemond · J. Feijen · R. J. Gaymans ( $\square)$

Department of Science and Technology, University of Twente,

217, Enschede 7500 AX, The Netherlands

e-mail: r.j.gaymans@tnw.utwente.nl

G. J. E. Biemond

Dutch Polymer Institute, 902, Eindhoven 5600 AX,

The Netherlands

e-mail: g.j.e.biemond@alumnus.utwente.nl

Present Address:

G. J. E. Biemond

Sabic-Europe, Geleen, The Netherlands relationship, but a modulus-yield stress relationship could not be established.

\section{Introduction}

Thermoplastic elastomers (TPEs) based on the segmented block copolymers display a two-phase morphology, with a continuous soft phase of low glass transition $\left(T_{\mathrm{g}}\right)$ and a phase-separated hard phase with a high transition temperature [1,2]. The phase-separated hard phase is the physical cross-links of the low $T_{\mathrm{g}}$ soft phase segments and also acts as a filler for the soft phase [1-4]. Segmented block copolymers often have a hard phase consisting of crystallized segments with a high melting temperature. Generally, segmented block copolymers are soft materials with a relatively low yield stress, high fracture strain and high fracture stress. With the increasing temperature, the modulus, yield stress the fracture stress decrease whereas the fracture strain increases, as is usually the case for polymers [1, 5-9]. The tensile and elastic properties of TPEs are sensitive to the type, concentration and morphology of the hard phase [1,2].

The hard segment (HS) crystallites have a nano-ribbonlike structure with a high aspect ratio [10-14], and these nano-ribbons reinforce the soft phase [3, 4, 15]. Upon stretching of such a copolymer, both the soft and the hard phases are deformed, and for a high enough strain, yielding of the hard phase occurs [13, 16-18]. During this yielding, the crystallites are sheared and their orientation changed (Fig. 1) [4, 13].

Upon straining of these materials, a dramatic decrease in the initial E-modulus is observed which is said to be due to a lowering of the aspect ratio of the ribbon-like crystallites 
Fig. 1 A schematic representation of the change in crystalline morphology of РТМО-ТФТ copolymers during straining: (a) long, randomly oriented crystalline ribbons; (b) broken up ribbons oriented in the strain direction; and (c) very small ribbons with an orientation perpendicular to the strain [16] (a)

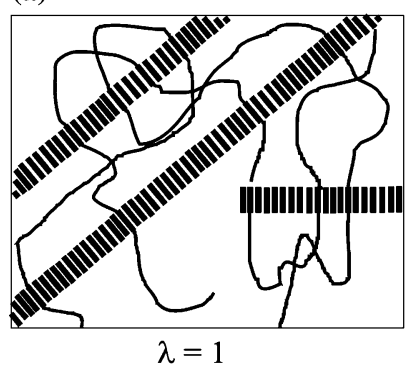

(b)

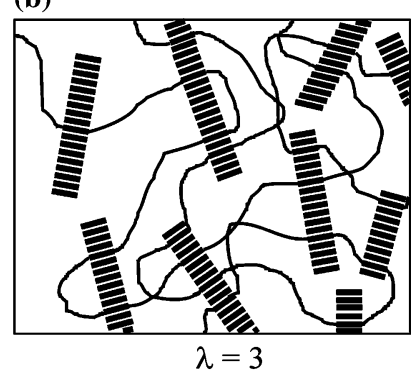

(c)

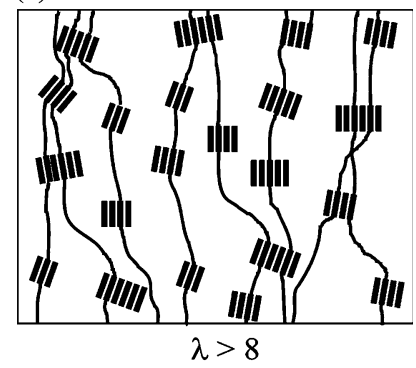

(Fig. 1b). At a strain of $200 \%$, the E-modulus can be lowered as much as tenfold and moreover, the ribbons become oriented in the stretching direction. At even higher stains, the ribbons are further broken up into crystallites with small aspect ratios and now also the small ribbons turn perpendicular to the stretching direction (Fig. 1c).

If the HSs are mono-disperse in length the copolymer has a lower soft segment $T_{\mathrm{g}}$, a sharper HS melting transition [2-4, 13-15, 18-25]. The mono-disperse segments crystallize fast and almost completely, and as a result, the soft phase contains very little dissolved HSs [3, 4, 14, 15, 17, 18]. The mono-disperse HSs have crystallites with nano-ribbon-like structures with high aspect ratios (i.e. 300-1,000) [2-4, 13-15, 18]. When the HSs are truly monodisperse the modulus is from room temperature to near the HS melting temperature, almost independent of temperature [2-4, 12-15, 18-25]. One can question whether this means that also the yield and fracture properties of these materials are also temperature independent.

Segmented copolymers with mono-disperse rigid segments have, at room temperature, a simple two-phase morphology. Interesting is to study the effect of the HS content and the temperature on the tensile properties of such a well-defined system. A PTMO P T6A6T system (Fig. 2), with an emphasis on $\mathrm{PTMO}_{2000}$-T6A6T [15], was chosen for this investigation.

$\mathrm{PTMO}_{\mathrm{x}}$-T6A6T segmented block copolymers have been defined as TPEs consisting of alternating soft (PTMO) and hard segments (T6A6T) [15]. The T6A6T segments have a symmetric structure with tetra-amide groups that can H-bond with both neighboring T6A6T units. The HSs crystallize into nano-ribbons that are dispersed in the continuous low $T_{\mathrm{g}}$ phase. These nano ribbons as observed with AFM have high aspect ratios. The crystallinity of the tetra-amide segment in the copolymers as measured by FT-IR was found to be very high, 80-90\% [15], and the $T_{\mathrm{m}}$ of the T6A6T segments in the copolymers was about $185{ }^{\circ} \mathrm{C}$ and slightly dependent on the content of PTMO segments. At room temperature the copolymers were elastic solids with an amorphous PTMO phase. The copolymer displayed, at room temperature, an excellent elastic behavior, which was probably due to the monodisperse HS and particular at low HS contents. Moreover, the PTMO segments were at room temperature able to strain-crystallize as a result of their enhanced ultimate properties.

However, the tensile properties as a function of temperature of such segmented block copolymers with the well-defined mono-disperse HS have, until now, barely been studied. This paper thus describes the investigation of the tensile properties of PTMO $_{\mathrm{x}}$-T6A6T polymers (Fig. 2) as a function of the PTMO length in the range of 650 $2,900 \mathrm{Da}$ as well as the influence of temperature on $\mathrm{PTMO}_{2000}$-T6A6T.

\section{Experimental section}

\section{Materials}

The PTMO $_{\mathrm{x}}$-T6A6T copolymers were synthesized according to the solution/melt polymerization route described in a previous study [15]. Dumbbell-shaped test bars were prepared by injection molding of the copolymers in an Arburg Allrounder 221-55-250 injection molding machine.

\section{Viscometry}

The solution viscosities were measured at a concentration of $0.1 \mathrm{~g} / \mathrm{dL}$ in a mixture of phenol/1,1,2,2-tetrachloroethane $\left(1: 1\right.$ molar ratio) at $25{ }^{\circ} \mathrm{C}$ using a capillary Ubbelohde type $1 \mathrm{~B}$. The inherent viscosities could then be calculated from these data. The value of the inherent viscosity was found to approach that of the intrinsic viscosity [26].

Fig. 2 The polymer structure of $\mathrm{PTMO}_{\mathrm{x}}-\mathrm{T} 6 \mathrm{~A} 6 \mathrm{~T}$

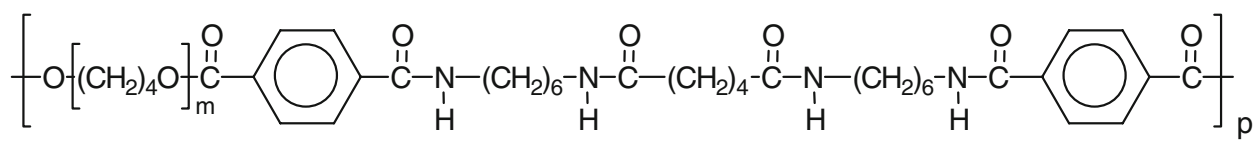


Dynamic mechanical thermal analyses

Samples $(70 \times 9 \times 2 \mathrm{~mm})$ for the dynamic mechanical thermal analyses (DMTA) measurements were prepared on an Arburg $\mathrm{H}$ manual injection molding machine, with a barrel temperature set $20^{\circ} \mathrm{C}$ higher than the melting temperature. The test samples were dried in vacuum at $50{ }^{\circ} \mathrm{C}$ for $24 \mathrm{~h}$ prior to analysis. DMTA thermograms were recorded with a Myrenne ATM3 torsion pendulum at a frequency of $1 \mathrm{~Hz}$ and $0.1 \%$ strain. The storage $\left(G^{\prime}\right)$ and loss $\left(G^{\prime \prime}\right)$ moduli were measured as functions of temperature. The samples were cooled to $-100{ }^{\circ} \mathrm{C}$ and subsequently heated at a rate of $1{ }^{\circ} \mathrm{C} / \mathrm{min}$. The temperature at the maximum of the loss modulus peak was taken as the glass transition temperature $\left(T_{\mathrm{g}}\right)$. The flow temperature $\left(T_{\text {flow }}\right)$ was defined as the temperature where the storage modulus reached $1 \mathrm{MPa}$. The start of the rubbery plateau, i.e., the intercept of the tangents, was denoted the flex temperature $\left(T_{\text {flex }}\right)$.

\section{Tensile tests}

Stress-strain curves were obtained on injection molded dumbbells (ISO37 type 2), using a Zwick Z020 universal tensile machine equipped with a $500 \mathrm{~N}$-load cell. The strain was measured with extensometers. The tensile tests were carried out at an initial strain rate of $0.4 \mathrm{~s}^{-1}$ (test speed of $60 \mathrm{~mm} / \mathrm{min}$ ). For test temperatures other than room temperature, a temperature-controlled environment chamber was used. The E-moduli at each temperature were determined in eightfold at a strain of $0.1-0.25 \%$. The standard deviation in the modulus was 5-8\%. Also measured were the stress at $10 \%$ strain $\left(\sigma_{10 \%}\right)$, the yield stress $\left(\sigma_{\mathrm{y}}\right)$, the yield strain $\left(\varepsilon_{\mathrm{y}}\right)$, the fracture stress $\left(\sigma_{\mathrm{b}}\right)$, the fracture strain $\left(\varepsilon_{\mathrm{b}}\right)$, and the true fracture stress $\left(\sigma_{\text {true }}\right)$. The true fracture stress was obtained by multiplying $\sigma_{\mathrm{b}}$ by the straining factor $\left(=1+\left(\varepsilon_{\mathrm{b}} / 100\right)\right)$.

\section{Results and discussion}

$\mathrm{PTMO}_{\mathrm{x}}$-T6A6T copolymers are transparent TPE materials with a well-defined morphology [15]. The $\mathrm{PTMO}_{\mathrm{x}}$ length was varied from 650 to $2900 \mathrm{Da}$, and the mono-disperse bisester tetra-amide segment T6A6T readily crystallized into nano-ribbons with high aspect ratios [15]. The T6A6T crystallinity was found to be high and, as a result, only little of the HS was dissolved in the PTMO phase. At room temperature, the copolymers had a two-phase structure; a rather pure PTMO phase with nano-crystallites from monodisperse T6A6T segments dispersed within it. However, if the PTMO was to undergo a strain-induced crystallization, the structure would become more complex. The copolymers all had high molecular weights and were processed by injection molding.

\section{DMTA}

The thermo-mechanical properties of the $\mathrm{PTMO}_{\mathrm{x}}-\mathrm{T} 6 \mathrm{~A} 6 \mathrm{~T}$ polymers were studied by DMTA. The storage and loss moduli were determined as functions of temperature (Fig. 3).

Three transitions were present in the graphs: the glass transition of the PTMO phase, the melting transition of the PTMO, and the melting transition of the T6A6T. A glass transition of the amorphous T6A6T phase, expected at a temperature of $125^{\circ} \mathrm{C}$, was not observed. The PTMO was found to be partly crystallized for PTMO lengths above 1,000 Da. The $T_{\mathrm{g}}$ of the soft phase of $\mathrm{PTMO}_{\mathrm{x}}-\mathrm{T} 6 \mathrm{~A} 6 \mathrm{~T}$ increased from $-70{ }^{\circ} \mathrm{C}$ for $\mathrm{PTMO}_{2900}$ and $\mathrm{PTMO}_{2000}$ to $-45^{\circ} \mathrm{C}$ for $\mathrm{PTMO}_{650}$ (Table 3). This increase in $T_{\mathrm{g}}$ was due to an increased density of physical cross-links [3]. The crystalline PTMO phase of the longer PTMO segments was expected to also contribute to the cross-link density. The low $T_{\mathrm{g}}$ values for the $\mathrm{PTMO}_{2900^{-}}$and $\mathrm{PTMO}_{2000^{-}}$based polymers indicated that the concentration of T6A6T segments in the polyether phase must be very low.

The melting temperature of the PTMO phase was identified as a shoulder on the $G^{\prime}$ and $G^{\prime \prime}$ curves in the DTMA graph (Fig. 3). A PTMO melting temperature was clearly present for samples with PTMO lengths of at least $1,400 \mathrm{Da}$ and ranged between 5 and $10^{\circ} \mathrm{C}$. The flex temperature $\left(T_{\text {flex }}\right)$, defined as the start of the rubber plateau, increased as a result of the crystalline PTMO phase melting temperature. The $T_{\text {flex }}$ was influenced by the $T_{\mathrm{g}}$ and the $T_{\mathrm{m}}$ of the PTMO; the higher $T_{\text {flex }}\left(0{ }^{\circ} \mathrm{C}\right)$ of $\mathrm{PTMO}_{650}$-T6T6T was due to the relatively high $T_{\mathrm{g}}\left(-45^{\circ} \mathrm{C}\right)$. Nevertheless, all the copolymers displayed $T_{\text {flex }}$ values below room

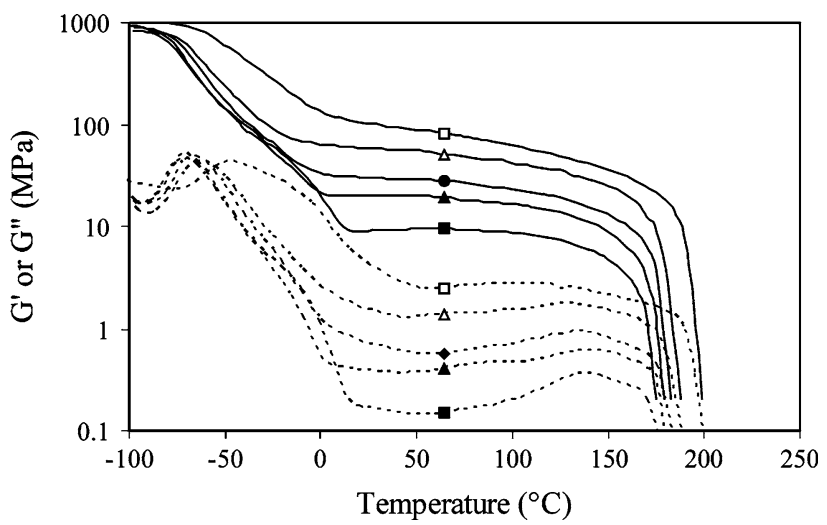

Fig. 3 Storage and loss modulus curves as functions of temperature for $\mathrm{PTMO}_{x}$-T6A6T with varying molecular weight of the PTMO segment: $\square, 650 \mathrm{~g} \mathrm{~mol}^{-1} ; \triangle, 1,000 \mathrm{~g} \mathrm{~mol}^{-1} ; \boldsymbol{\bullet}, 1,400 \mathrm{~g} \mathrm{~mol}^{-1} ; \boldsymbol{\Delta}$, $2,000 \mathrm{~g} \mathrm{~mol}^{-1} ; \mathbf{\square}, 2,900 \mathrm{~g} \mathrm{~mol}^{-1}$ 
temperature. Thus in the isotropic state at room temperature the copolymer had a two phase structure.

The copolymers had above room temperature rubber moduli that were almost temperature-independent (about $0.4 \%$ change per degree $\mathrm{C}$ ). This is typical for copolymers with crystallizable segments of mono-disperse length [2-4, 13-15, 18-25] The flow temperatures decreased with increasing PTMO length and corresponded well with the melting temperatures recorded with DSC [15]. The decrease in melting temperature $\left(T_{\text {flow }}\right)$ of T6A6T with PTMO content has been explained as a result of the solvent effect of the PTMO on the HS crystals [3, 4, 13-15, 18].

The storage modulus at room temperature $G_{25}^{\prime}{ }^{\circ} \mathrm{C}$ for the copolymers decreased drastically with increasing length of the flexible segment and thus with decreasing amide content (Figs. 3 and 5). This significant change in modulus was partly due to the changing crosslink density but mainly a result of the decreasing HS content, which gave rise to a decrease in the reinforcing effect of the HS crystallites [3, 15]. The reinforcing effect of the crystallites was a function of the crystalline content as well as of the aspect ratio of these crystallites. The aspect ratio of the T6A6T crystallites in the copolymers was high [15].

\section{Tensile properties at room temperature}

Tensile properties of the segmented block copolymers were studied on injection molded dumbbell samples (ISO37 s2). The stress-strain curves were typical of thermoplastic elastomeric materials with crystalline HS which deform on yielding (Fig. 4, Table 1).

At small deformations, the stress increased fairly linearly with the strain (Hooke's law) [5-9]. Above the yield strain, the stress gradually increased, and at strains higher than $200 \%$ strain-hardening took place.

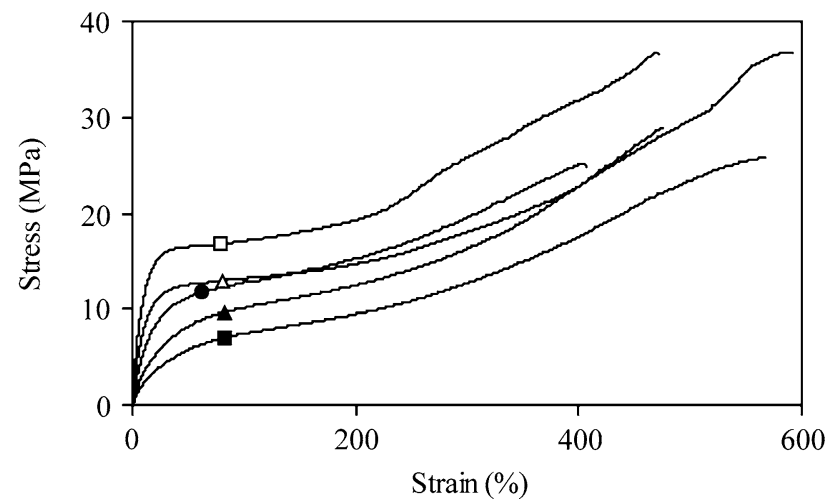

Fig. 4 Stress-strain curves for $\mathrm{PTMO}_{\mathrm{x}}$-T6A6T at room temperature with varying molecular weight of the PTMO segment: $\square, 650 \mathrm{~g} \mathrm{~mol}^{-1}$; $\triangle, \quad 1,000 \mathrm{~g} \mathrm{~mol}^{-1} ; \quad \boldsymbol{\bullet}, 1,400 \mathrm{~g} \mathrm{~mol}^{-1} ; \mathbf{\Lambda}, 2,000 \mathrm{~g} \mathrm{~mol}^{-1}$; $2,900 \mathrm{~g} \mathrm{~mol}^{-1}$
The E-modulus increased strongly with the concentration of tetra-amide segment as was also the case for the storage $G^{\prime}$-modulus (Fig. 5). The underlying explanation for this effect on the E-modulus was thus the same as that for the $G^{\prime}$ modulus. For the PTMO copolymers with zero HS concentration the $G^{\prime}$ and E moduli were approximately 1 and $3 \mathrm{MPa}$, respectively.

The Young (E) and storage $\left(G^{\prime}\right)$ moduli are related according to $[5-9,26]$ :

$G^{\prime}=\frac{E}{2(1+v)}$

where $v$ is the Poison ratio.

For an ideal elastomer the Poison constant has a value of 0.5 and corresponding $\mathrm{E} / G^{\prime}$ ratio is 3 . An $\mathrm{E} / G^{\prime}$ ratio of 3 was obtained for the studied copolymers.

The reinforcing effect of the ribbon-like crystallites can be modeled. There are several mechanical models that describe the modulus of a composite as a function of filler content $[27,28]$. The Halpin-Tsai model calculates the elastic modulus of a fiber composite with randomly oriented fibers as a function of fiber content and aspect ratio [27-30]. The Halpin-Tsai model has been applied to semicrystalline polymers [31] as well as to segmented block copolymers [3, 15], and was chosen for modeling the modulus in the present study. In this calculation, it was assumed that the crystallinity of the amide segments was $88 \%$. The following parameters were used for calculating the E-modulus according to the Halpin-Tsai relationship: the E-modulus of the matrix polymer (PTMO) was $3 \mathrm{MPa}$; the E-modulus of the reinforcing phase (crystalline amide) was $5,000 \mathrm{MPa}$; the aspect ratio of the crystallites was 1,000. A detailed description of the calculations can be found elsewhere [32].

The increase in E-modulus as described by the HalpinTsai model (dashed line) displayed a reasonable fit with the experimental results of the E-modulus (Fig. 5). Thus, the strong increase in modulus with amide content of the segmented block copolymers could be explained by the high amide crystallinity and the high aspect ratio of the crystallites.

As with very soft materials, the initial modulus is not always easy to measure accurately. Therefore, a stress at $10 \%$ strain is sometimes given. For a Hookean material, the initial modulus and the stress at $10 \%$ strain, a strain below the yield strain, should give similar values. The tensile tests for the PTMO copolymers with mono-disperse HS showed that the stresses at $10 \%$ strain were lower than expected from the initial modulus values (Table 1). This implies that plastic deformation had taken place well before the yield strain (at 25-66\% strain). Segmented block copolymers often display significant strain-softening believed to be due to the break-up of the long crystalline ribbons [4, 10-13]. 
Table 1 Tensile properties of the $\mathrm{PTMO}_{\mathrm{x}}$-T6A6T copolymers

\begin{tabular}{lllllllllll}
\hline & $\begin{array}{l}\text { T6A6T } \\
(\text { wt.\% })\end{array}$ & $\begin{array}{l}\eta_{\text {inh }} \\
(\mathrm{dL} / \mathrm{g})\end{array}$ & $\begin{array}{l}G^{\prime} \text {-modulus } \\
(\mathrm{MPa})\end{array}$ & $\begin{array}{l}\text { E-modulus } \\
(\mathrm{MPa})\end{array}$ & $\begin{array}{l}\mathrm{E} / G^{\prime} \\
(-)\end{array}$ & $\begin{array}{l}\sigma_{10 \%} \\
(\mathrm{MPa})\end{array}$ & $\begin{array}{l}\varepsilon_{\mathrm{y}} \\
(\%)\end{array}$ & $\begin{array}{l}\sigma_{\mathrm{y}} \\
(\mathrm{MPa})\end{array}$ & $\begin{array}{l}\varepsilon_{\mathrm{b}} \\
(\%)\end{array}$ & $\begin{array}{l}\sigma_{\mathrm{b}} \\
(\mathrm{MPa})\end{array}$ \\
\hline $\mathrm{PTMO}_{650}$ & 43.8 & 1.8 & 102 & 311 & 3.0 & 11.3 & 25 & 16 & 471 \\
$\mathrm{PTMO}_{1,000}$ & 34.2 & 2.5 & 51 & 133 & 2.6 & 7.95 & 29 & 12 & 59 \\
$\mathrm{PTMO}_{1,400}$ & 27.1 & 1.5 & 30 & 87 & 2.9 & 5.62 & 42 & 11 & 43 & 407 \\
$\mathrm{PTMO}_{2,000}$ & 21.1 & 2.9 & 20 & 46 & 2.3 & 3.40 & 49 & 9 & 476 & 25 \\
$\mathrm{PTMO}_{2,900}$ & 15.7 & 3.5 & 9 & 29 & 3.2 & 2.28 & 66 & 6 & 568 & 26 \\
\hline
\end{tabular}

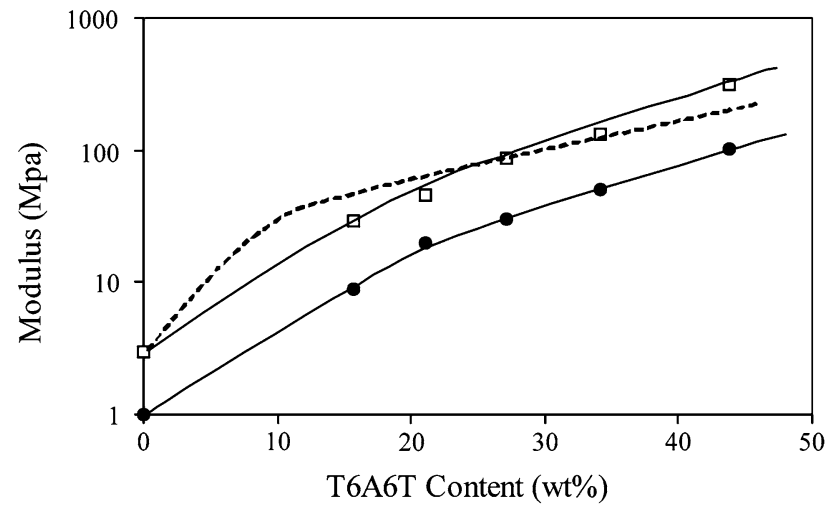

Fig. $5 G^{\prime}$ and E moduli as functions of the T6A6T content: $\square$, E-modulus;,$G^{\prime}$-modulus. The Halpin-Tsai relationship for the E-modulus (dashed line) is also presented

The yield strain increased with increasing PTMO length and thus also with decreasing T6A6T content (Table 1 and Fig. 6). A higher strain was therefore needed with decreasing T6A6T content before the crystals were sufficiently stressed to yield. The yield stress increased linearly with the T6A6T content (Fig. 6). As both the (log) modulus and the yield stress were directly related to the crystallinity, the yield stress-(log) modulus relationship should be simple $[6,18,33-36]$. The yield stress-(log) modulus relationship is often studied on polyethylene [33-35],

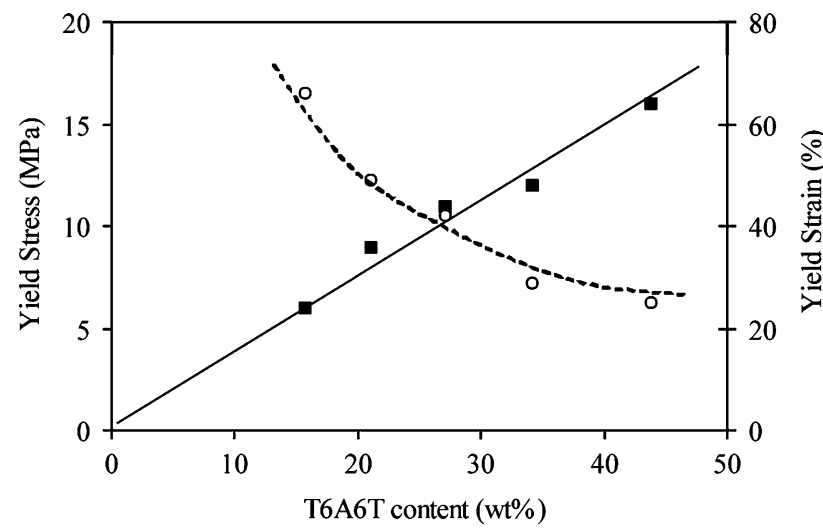

Fig. 6 The yield stress, $\mathbf{\square}$, and yield strain; $\bigcirc$, as functions of the T6A6T content however in these studies the PE crystallite thickness is frequently changed at the same time as the PE crystallinity and probably also the aspect ratio of the crystallites. Since the T6A6T segments of the studied segmented block copolymers were mono-disperse in length, the crystallite thickness in these copolymers was expected to be constant and also the crystallinity of the T6A6T segments was constant. The yield stress was found to increase linearly with the $\log$ modulus (Table 1). However, since the crystalline ribbons were broken up far before the yield stress was attained, the structure at the initial modulus differed from that at the yield point strain, and therefore a physical meaning for a yield stress-(log) modulus relationship for these materials was not present.

At higher strains, there was an upsweep in the stressstrain curve due to strain-hardening. This effect was strong for all the studied segmented copolymers at room temperature, even those with lower $\mathrm{PTMO}_{\mathrm{x}}$ length. The strainhardening could result from strain crystallization of either the PTMO or the T6A6T segment, but seeing as the T6A6T segments were already highly crystalline, the strain-hardening was thought to be mainly caused by the PTMO segments. It was surprising to see that even copolymers with $\mathrm{PTMO}_{650}$ and $\mathrm{PTMO}_{1000}$ that were amorphous in the unoriented state had a strong strain-hardening effect. Upon straining of the polymer, PTMO chains became aligned and were able to crystallize with a higher melting temperature $\left(43{ }^{\circ} \mathrm{C}\right)$ than the unoriented PTMO $\left(0{ }^{\circ} \mathrm{C}\right)$ [37].

The fracture strains and fracture stresses were found to be high. Spun fibers of similar segmented copolymers with smooth surfaces could easily reach strains at break of over $1,000 \%$ [36-38]. This is higher than the natural draw ratio of coiled chains $(600-700 \%)$ [5-9].

\section{Influence of temperature on tensile behavior}

In general, the temperature has a strong effect on the tensile properties of multiphase segmented block copolymers. At sub-zero temperatures (below $T_{\text {flex }}$ ), the materials lose their typical elastomeric character. Above the $T_{\text {flex }}$, on the other hand, the stress levels in the tensile curve decrease with increasing temperature. 


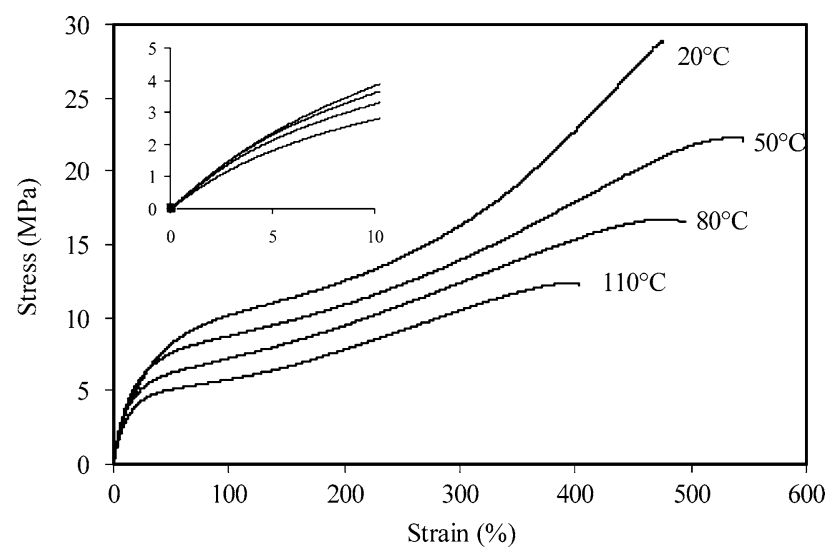

Fig. 7 Stress-strain curves for $\mathrm{PTMO}_{2000}-\mathrm{T} 6 \mathrm{~A} 6 \mathrm{~T}$ at various temperatures

The tensile properties of $\mathrm{PTMO}_{2000}-\mathrm{T} 6 \mathrm{~A} 6 \mathrm{~T}$ as functions of temperature were studied in the temperature range 20 $110{ }^{\circ} \mathrm{C}$ (Fig. 7 and Table 2). This temperature range was above the $T_{\text {flex }}$ and well below the HS melting temperature of the copolymer $\left(183{ }^{\circ} \mathrm{C}\right)$.

The initial E-modulus was found to be unchanged with increasing temperature, however, the stress at $10 \%$, the yield stress, the yield strain and the fracture strain all decreased with increasing temperature. A clear strainhardening effect was only observed at room temperature. Increasing the temperature the yield stress was found to decrease. Also the fracture strain did not increase and possibly even decreased.

\section{E-modulus}

The Young modulus (E) remained fairly constant with increasing temperature as did the shear storage modulus $\left(G^{\prime}\right)$. This is typical for segmented block copolymers with rigid segments of mono-disperse length $[2-4,13-15,18-$ 24]. The temperature-independency of the E- and $G$-modulus indicates that the HS crystallinity and the aspect ratio of the crystallites did not change upon heating. This is thought to be due to the fact that the mono-disperse segments crystallized over their full length. A fringed layer on the crystallites, which melts at lower temperatures, was not present. The crystallites melted over a narrow temperature range and not over a broad range. The ratio of $\mathrm{E} / G^{\prime}$ for these copolymers was $\sim 3$ and did not change with temperature (Table 2).

\section{Stress at $10 \%$ strain}

The stress at $10 \%$ strain decreased by $36 \%$ when the temperature was increased from 20 to $110{ }^{\circ} \mathrm{C}$, while, the E-modulus remained unchanged (Table 2). The stress at $10 \%$ strain on other TPEs decreased even stronger [39]. Already at $10 \%$ strain a strain softening was taking place and with increasing temperature, a more significant strainsoftening seemed to take place. This means that at higher temperature the crystallites deformed more easily.

\section{Yield behavior}

The yield point is generally seen as a point of onset for a substantial plastic deformation [5-9]. For many applications, a deformation beyond the yield point would be undesirable. For semi-crystalline polymers the yield stress decreases more or less linearly with temperature (Table 2 and Fig. 8). This again suggested a strain-softening, due to the break-up of the crystalline ribbons, which increased with temperature. The crystalline ribbons deformed at higher temperatures at lower stresses. The yield strain also deceased with temperature and this is unusual. The lowing of the yield strain with increasing temperature suggests that at higher temperatures the HS crystallites are more easily deformed.

The yield stress as a function of strain rate and temperature can be described by the Eyring relationship [5, 6, 8]. For the studied copolymers with a constant modulus, this relationship describes the strain-softening behavior of the crystallites.

$\frac{\sigma_{\mathrm{y}}}{T}=\frac{R}{v}\left(\frac{\Delta H}{R T}+\ln \frac{2 \dot{e}}{\dot{e}_{0}}\right)$

Here, $\sigma_{\mathrm{y}}$ is the yield stress, $v$ the activation volume, $\Delta H$ the activation enthalpy, $R$ the gas constant, $T$ the temperature, $\dot{e}$ the strain rate, and $\dot{e}_{0}$ is a constant. A linear relationship is obtained if $\sigma_{\mathrm{y}} / T$ is plotted as a function of the reciprocal temperature $\left(\sigma_{\mathrm{y}} / T\right.$ vs. $\left.1 / T\right)$. Linearity is to be expected

Table 2 Tensile results for $\mathrm{PTMO}_{2000}-\mathrm{T} 6 \mathrm{~A} 6 \mathrm{~T}$ at various temperatures, $\eta_{\mathrm{inh}}=2.2 \mathrm{dL} / \mathrm{g}$

\begin{tabular}{|c|c|c|c|c|c|c|c|c|c|}
\hline Temperature & $G^{\prime}(\mathrm{MPa})$ & E-Modulus (MPa) & $\mathrm{E} / G^{\prime}(-)$ & $\sigma_{10 \%}(\mathrm{MPa})$ & $\sigma_{\mathrm{y}}(\mathrm{MPa})$ & $\varepsilon_{\mathrm{y}}(\%)$ & $\sigma_{\mathrm{b}}(\mathrm{MPa})$ & $\varepsilon_{\mathrm{b}}(\%)$ & $\sigma_{\text {true }}^{\mathrm{a}}(\mathrm{MPa})$ \\
\hline $20{ }^{\circ} \mathrm{C}$ & 20 & 53 & 2.7 & 4.5 & 8.7 & 49 & 29 & 480 & 165 \\
\hline $50{ }^{\circ} \mathrm{C}$ & 20 & 59 & 3.0 & 3.8 & 7.2 & 42 & 22 & 550 & 143 \\
\hline $80^{\circ} \mathrm{C}$ & 18 & 56 & 3.1 & 3.4 & 5.8 & 37 & 17 & 490 & 98 \\
\hline $110^{\circ} \mathrm{C}$ & 16 & 53 & 3.3 & 2.9 & 4.7 & 33 & 12 & 400 & 61 \\
\hline
\end{tabular}

${ }^{\mathrm{a}} \sigma_{\text {true }}$ was obtained by multiplying $\sigma_{\text {break }}$ with the straining factor $\left(=1+\left(\varepsilon_{\text {break }} / 100\right)\right)$ 


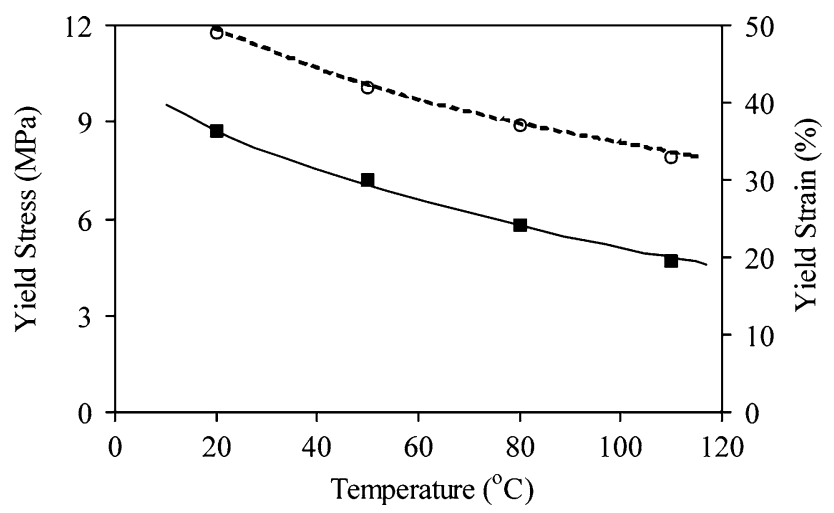

Fig. 8 The tensile properties of $\mathrm{PTMO}_{2000}-\mathrm{T} 6 \mathrm{~A} 6 \mathrm{~T}$ as functions of temperature. $\mathbf{\square}$, yield stress; $\bigcirc$, yield strain

when one unique flow mechanism controls the yield stress. An Eyring plot was made for $\mathrm{PTMO}_{2000}-\mathrm{T} 6 \mathrm{~A} 6 \mathrm{~T}$ ( $\sigma_{\mathrm{y}} / T$ vs. $1 / T$ ) and a linear relationship was obtained (Fig. 9). This indicates that the yield behavior can be described by this relationship.

\section{After the yield point}

At strains higher than the yield strain the engineering stresses increased steadily. Moreover, necking was absent during the tensile measurement indicating that no localization of stress took place. At room temperature and $>200 \%$ strain, a significant strain-hardening effect was observed. This was believed to be the result of a straininduced crystallization of the $\mathrm{PTMO}_{2000}$ segments [4]. The $\mathrm{PTMO}_{2000}$ segments at room temperature in the unoriented state are amorphous; however, on orientation the melting temperature of $\mathrm{PTMO}_{2000}$ increased to $43{ }^{\circ} \mathrm{C}$ and straininduced crystallization can take place [37]. The fact that the strain crystallization of $\mathrm{PTMO}_{2000}$ at higher temperatures $\left(>50^{\circ} \mathrm{C}\right)$ did not take place was probably due to the

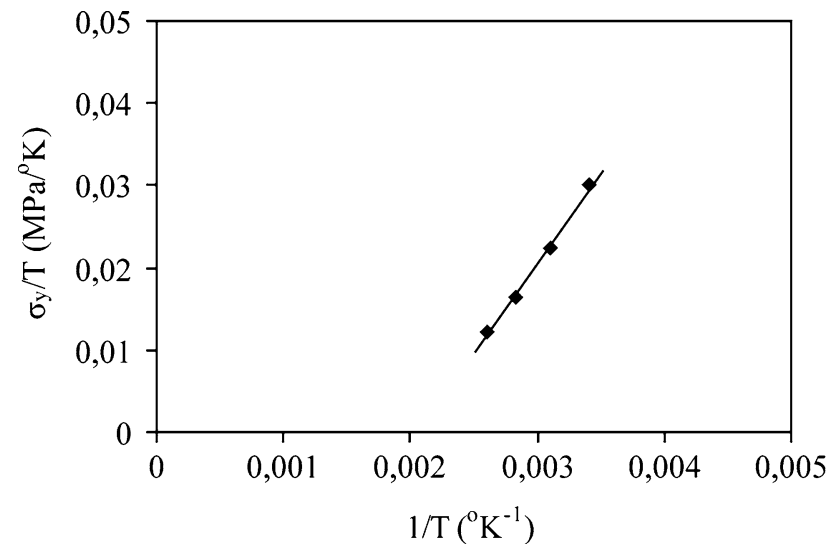

Fig. 9 An Eyring plot $\sigma_{\mathrm{y}} / T$ vs $1 / T$ for $\mathrm{PTMO}_{2000}-\mathrm{T} 6 \mathrm{~A} 6 \mathrm{~T}$ at 20,50 , 80 , and $110{ }^{\circ} \mathrm{C}$ test temperature being higher than the melting temperature of the strained crystallized PTMO segments $\left(43^{\circ} \mathrm{C}\right)$.

\section{Fracture behavior}

The fracture properties are very sensitive to the molecular weight and strain-hardening of a copolymer. Normally, the fracture stress decreases with increasing temperature whereas the fracture strain increases [5-9, 25]. Moreover, the fracture stress is often less dependent on temperature than the yield stress. At room temperature the fracture stress was high (Fig. 7) as a result of the strain-induced crystallization of the PTMO segments. With increasing temperature to $110{ }^{\circ} \mathrm{C}$, a decrease in both the stress and the strain at break was observed. A single parameter for the fracture stress and the fracture strain is the true fracture stress, and also this parameter displayed a strong decrease with temperature (Table 2). Strain hardening stabilizes the deformation and the absence of strain hardening at higher temperatures lowered both the fracture strain and the fractures stress.

\section{Conclusions}

The tensile properties of segmented copolymers comprised of PTMO flexible segments and mono-disperse segments were studied. The PTMO length was varied from 650 to 2,900 $\mathrm{Da}$ and the test temperature from 20 to $110^{\circ} \mathrm{C}$. The mono-disperse T6A6T segments had a very high crystallinity and the crystallites displayed a nano-ribbon structure with very high aspect ratios. Both the storage $\left(G^{\prime}\right)$ modulus and the Young modulus increased strongly with T6A6T content, and this significant increase in modulus could be modeled by a fiber composite model. Parameters in this modulus increase are the crystalline content and aspect ratio of the crystallites. The modulus also barely changed with temperature, suggesting that the properties of the polyether matrix, the properties of the T6A6T crystallite, the T6A6T crystallinity as well as the crystallite aspect ratio remained unchanged. The stress values at $10 \%$ strain, i.e., well below the yield strain, were lower than for a material with a Hookean behavior. This suggests that a certain amount of strain-softening took place at $10 \%$ strain, and this strain-softening we think was due a lowering of the aspect ratio of the crystallites (Fig. 1).

With increasing mono-disperse HS, the yield stress increased linearly whereas the yield strain displayed a linear decrease. The change in yield stress as a function of temperature could be modeled by the Eyring model. As at room temperature both the (log) modulus and the yield stress were linearly related to the T6A6T content (T6A6T crystallinity), it was deemed of interest to study the 
modulus-yield stress relationship. However, strain-softening already occurred prior to the yield point and the structure of the crystallites at the yield point must have been different from that at the point where the modulus was determined. Also the yield stress decreased with temperature while the modulus hardly changed. Thus it is not sensible to study a yield stress-(log) modulus relationship, a direct comparison was not meaningful.

At room temperature and strains $>200 \%$ a strain-hardening was seen, and this even for $\mathrm{PTMO}_{650}$ and $\mathrm{PTMO}_{1000}$ that were amorphous in the isotropic state. This strainhardening effect for the copolymers was strong and was believed to be due to the PTMO segments and not T6A6T. This was confirmed by the result that the strain-hardening was absent when the temperature was increased above the melting temperature of the oriented PTMO.

Acknowledgments This research was financed by the Dutch Polymer Institute (DPI, The Netherlands), project number 137.

Open Access This article is distributed under the terms of the Creative Commons Attribution Noncommercial License which permits any noncommercial use, distribution, and reproduction in any medium, provided the original author(s) and source are credited.

\section{References}

1. Holden G, Legge NR, Quirk R, Schroeder HE (1996) Thermoplastic elastomers. Hanser, Munich

2. Fakirov S (2005) Handbook of condensation thermoplastic elastomers. Wiley, New York

3. Van der Schuur JM, Gaymans RJ (2006) J Polym Sci Polym Chem 44:4769. doi:10.1002/pola.21587

4. Niesten MCEJ, Gaymans RJ (2001) Polymer 42:6199. doi:10.1016/S0032-3861(01)00088-X

5. Ward IM (1979) Mechanical properties of solid polymers. Wiley, New York

6. Browstow W, Cornelissen RD (1986) Failure of plastics. Hanser, Munich

7. Hertzberg RW (1989) Deformation and fracture mechanics of engineering materials. Wiley, New York

8. Mc Crum NG, Buckley CP, Bucknall CB (2001) Principles of polymer engineering. Oxford University Press, New York

9. Rodriguez F, Cohen C, Ober C, Archer LA (2005) Principles of polymer system. Taylor \& Francis, New York

10. McLean RS, Sauer BB (1999) J Polym Sci Polym Phys 37:859. doi:10.1002/(SICI)1099-0488(19990415)37:8<859::AID-POLB $11>3.0 . \mathrm{CO} ; 2-\mathrm{U}$

11. Garrett JT, Runt J, Lin JS (2000) Macromolecules 33:6353. doi: $10.1021 / \mathrm{ma} 000600 \mathrm{i}$
12. Seth JP, Xu J, Wilkes GL (2003) Polymer 44:743. doi:10.1016/ S0032-3861(02)00798-X

13. Sauer BB, McLean S, Gaymans RJ, Niesten MCEJ (2004) J Polym Sci Polym Phys 42:1783. doi:10.1002/polb.20060

14. Versteegen RM, Kleppinger R, Sijbesma RP, Meijer EW (2006) Macromolecules 39:772. doi:10.1021/ma051874e

15. Biemond JE, Feijen J, Gaymans RJ (2007) J Appl Polym Sci 105:951. doi:10.1002/app.26202

16. Bonart R, Morbitzer L, Hentze J (1969) J Macromol Sci Phys 3:337. doi:10.1080/00222346908205099

17. Sauer BB, McLean RS, Brill DJ, Londono DJ (2002) J Polym Sci Polym Phys 40:1727. doi:10.1002/polb.10234

18. Niesten MCEJ, Gaymans RJ (2001) Polymer 42:6199. doi:10.1016/S0032-3861(01)00088-X

19. Harrell LJ (1969) Macromolecules 2:607. doi:10.1021/ma600 $12 \mathrm{a} 008$

20. Eisenbach CD, Baumgartner M, Guenter C (1986) In: Lai J, Mark JE (eds) Advances in elastomer and rubber elasticity. Plenium, New York

21. Eisenbach CD, Nefzger H (1989). In: Cumbertson WM (ed) Multiphase macromolecular systems. Contemporary topics in polymer science, vol 6. Plenium, New York

22. Versteegen RM, Kleppinger R, Sijbesma RP, Meijer EW (2006) Macromolecules 39:772. doi:10.1021/ma051874e

23. Sheth JP, Klinedinst DB, Wilkes GL, Yilgor I, Yilgor E (2005) Polymer 46:7317. doi:10.1016/j.polymer.2005.04.041

24. Das S, Klinedinst DB, Yilgor I, Yilgor E Beyer FL, Cox DF, Wilkes GL (2006) J Macromol Sci B: Phys 46:853. doi:10.1080/ 00222340701388805

25. Krijgsman J, Husken D, Gaymans RJ (2003) Polymer 44:7573. doi:10.1016/j.polymer.2003.09.043

26. Cowie JMG (1991) Polymers: chemistry and physics of modern materials, 2nd edn. Blackie, London

27. Thomason JL, Vlug MA (1966) Composites 27A:477

28. Cox HL (1952) Br J Appl Phys 3:72. doi:10.1088/0508-3443/3/3/ 302

29. Cottrell AH (1964) Proc R Soc A282:2

30. Halpin JC, Kardos JL (1972) J Appl Phys 43:2235. doi:10.1063/ 1.1661482

31. Van der Schuur JM, Gaymans RJ (2006) J Polym Sci Part A 44:4769

32. Van der Schuur JM (2004) Thesis, Appendix A. Twente University, Enschede

33. Peacock J (2000) Handbook of polyethylene. Marcel Dekker, New York

34. Graham JT, Alamo RG, Mandelkern L (1997) J Polym Sci Polym Phys 35:213. doi:10.1002/(SICI)1099-0488(19970130) 35:2<213::AID-POLB2>3.0.CO;2-T

35. Buckley C, Fisher CJ, Howard PR (1989) Macromolecules 22:1709. doi:10.1021/ma00194a035

36. Niesten MCEJ, Krijgsman J, Harkema S, Gaymans RJ (2001) J Appl Polym Sci 82:2194. doi:10.1002/app.2067

37. Niesten MCEJ, ten Brinke JW, Gaymans RJ (2001) Polymer 42:2001

38. Krijgsman J, Gaymans RJ (2003) Polymer 45:437

39. Arnitel data sheet. http://www.dsm.com 